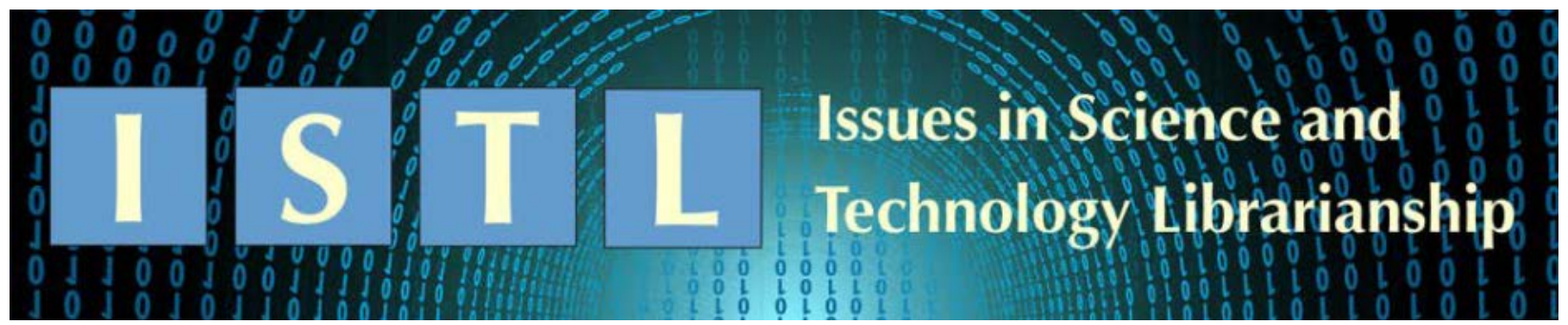

\title{
The Research Lab as Satellite Library
}

\author{
Mason Brown \\ Science Resources Librarian \\ CUNY Graduate Center \\ mbrown3@gc.cuny.edu
}

\begin{abstract}
It is challenging to identify the needs of researchers and students at any satellite campus, a situation that is exacerbated when the satellite campus is a research laboratory. The users are not taking classes, but still have library support needs. This article discusses the difficulties in properly identifying a population of students at this type of institution, as well as the associated challenges that come with developing a series of library workshops for different groups of users.
\end{abstract}

\section{The Advanced Science Research Center (ASRC)}

The Advanced Science Research Center (ASRC) is a dedicated laboratory research space that falls under the City College of New York (CUNY) consortial umbrella; specifically, under the banner of the CUNY Graduate Center (GC). The ASRC has five Research Initiatives covering five different scientific disciplines: Nanoscience, Photonics, Structural Biology, Neuroscience, and Environmental Science, with 49 research faculty among them. In addition to these full-time faculty, there are currently 50 graduate students, 10 master's students, and 40 postdoctoral fellows. These students all have primary affiliations with other schools that are part of CUNY. Some of these students are focusing on their thesis research in the various ASRC labs, others are still taking classes while working at the ASRC, and the postdocs are developing the skills and the relationships that they will need to be successful scientists. This leads to a very disparate group of people, with a complex set of library and research support needs. For the purposes of this paper, undergraduates, graduates, and postdoctoral scholars will all be referred to as "students."

It has been well reported that meeting the research needs of constituents on a satellite campus is a challenging endeavor. Nicholson and Eva (2001) report that one of the hallmarks of a successful bibliographic instruction (BI) program is that it is directly tied to course assessment. This is not always possible at a research lab that is also a satellite campus. ASRC students need BI sessions that are directly tied to their professional development. Many of these students primarily interact with the faculty who are running their labs. These faculty are, for the most part, non-teaching faculty. Not only does this mean that the students' day-to-day work does not have a direct connection to receiving a grade in a class, but because the faculty do not have any teaching requirements, this lessens the possibility that these faculty will have any regular interaction with a librarian as a resource for their students. Recent studies suggest that faculty buy-in for BI is essential (Miller \& Neyer 2016; Whearty et al. 2017), and one efficient path to 
the students is through faculty with whom the librarian has a pre-existing professional relationship. If both the students and the faculty are unaware of the benefits of library involvement in their professional development, then these are two hurdles that will need to be overcome.

Some of the challenges come from a pre-existing sense of confusion and ambivalence towards the library, mostly due to a series of changes to on and off campus access. The ASRC is a relatively new institution, and their access methods have been changing frequently. At first, ASRC researchers and students had access to library materials through the CUNY central offices, which oversee the libraries on all campuses. Administration was then transferred to a different CUNY campus, City College, which led to a new set of credentials. Access was again shifted to the Graduate Center, requiring them to use yet another set of usernames and passwords, which were separate from their ASRC credentials. To further complicate matters, the IP range at the ASRC was, until recently, not included in the recognized ranges by service providers. This meant that even though the ASRC researchers were being continually told that they were part of the Grad Center, and that all of the on-line instructional materials suggested that log-ins were not required for on campus users, any onsite users at the ASRC would still have to $\log$ in. This has been considerably streamlined recently, when the ASRC's IP range was registered with vendors so that users do not need to log in to resources while on campus. These changes will help to make access as easy as possible, thereby removing one barrier to efficient research.

A further unexpected challenge came from the disconnect between the perceived student interest in BI seminars and the actual attendance. In the summer before the seminar series started, a survey was sent out to the students at the ASRC, and nine completed questionnaires were returned. This survey asked the students to pick the topics they would be most interested in from a provided list. It is possible that an opportunity to collect more relevant data from the students was missed because the surveys did not allow for free form answers from the students. The most popular responses were for workshops on access, advanced Web of Science usage, Zotero, open access journals, and predatory publishing. These results were used as a starting point for workshop development.

Attendance was minimal at the instruction sessions. Every session had at least one attendee, a regular who came to each session. The best attendance was recorded at the workshop on citation management tools, with three students in the classroom. Two students attended the session on accessing articles and databases from on and off campus, and one at the workshops on predatory publishing, on open access, and on institutional repository use.

These seminars were initially scheduled to take place directly after weekly Science Cafe events, wherein members of the various initiatives at the ASRC spend 15 minutes discussing their research and their role in the building, followed by questions, coffee, and pastries. The expectation was that the collegial atmosphere of these events would lead to increased attendance at the BI sessions, but the opposite effect was observed to be true. Due in part to the busy schedules that active lab research demands, oftentimes students and faculty in the building did not have the available time to spend an extra hour away from their labs, immediately after an hour of socializing and networking. This upcoming semester, the sessions have been scheduled on a different day, which may avoid meeting burnout with the students and increase attendance.

Other studies (Hufford 2004; Carroll et al. 2016) stress the value in the production of a webbased library skills course to help off site learners. This is not a useful solution for the ASRC. The students and faculty in the research labs are not actively taking courses at the ASRC, 
therefore they do not have specific curricular goals. They need the BI sessions to be more focused on practical skills that can be of use to scientists and researchers. When the BI sessions for the ASRC were initially developed, they were modelled on an existing series of classes that were regularly given to graduate students. It quickly became apparent that the scientists there, which included both the research faculty and the students, were not interested in this model of library instruction. The sessions needed to be revised to appeal primarily to ASRC affiliates as professionals. For example, in the session on using institutional repositories and open access journals, the traditional focus is on how students can take advantage of these tools to find freely and legally available versions of articles to which they might not otherwise have access. For the updated ASRC version of this class, the focus was changed so that the majority of the time was spent discussing how producers of information can make their own writing more accessible, and how they can legally put their writings into the appropriate repositories. The hope was that by shifting the conversation to the ways these tools can directly benefit researchers, the sessions would be more relevant. It was late in the semester when these changes were made, and it is likely that there had not been time enough to implement and advertise them properly. The focus of all future workshops will be on the students as researchers instead of as traditional students, and this will be reflected in publicity materials.

It is essential to communicate to the students not only that a series of workshops has been scheduled, but also that there was value in attending. There is a building-wide network of digital signs, and posters for each class were displayed well in advance of the scheduled dates. A survey of attendees at the sessions revealed that the majority of students had not seen the digital posters, which might be due to the fact that so many events happen in the building daily that individual posters can easily get lost in the shuffle. The directors and administrators of the 5 research initiatives contacted the members of their units about the workshops, and the majority of the attendees reported that this was how they heard about the sessions. The ASRC recently appointed a full-time director and getting her support has proved invaluable. The most successful method for communicating has been an initial announcement from the departments a week before the sessions, and a reminder from the director on the morning of the session.

One associated challenge still to be overcome is how best to convey the content of the workshops. As discussed above, these workshops need to clearly address a professional interest. Workshops that teach advanced database usage have been among the most sparsely attended, perhaps due to the perception that the students and scientists working in these labs are already professional researchers, and that this level of training is irrelevant. Tactics were changed in the Spring 2020 semester, and instead of offering an advanced Web of Science searching workshop, a workshop on citation searching and advanced results analysis was offered. Although the workshop covered much of the same information, rebranding it to focus on the specific skills being taught can potentially attract a larger audience.

Working at a satellite campus presents a unique series of challenges, which are further compounded by the fact that this particular satellite campus is a fully functioning, state of the art research laboratory. It is hoped that by describing some of the challenges faced in identifying the unique needs of this population, readers working with satellite campuses and research labs will be better prepared to provide the best possible service to their constituents. 


\section{References}

Carroll, A. J., Tchangalova, N. \& Harrington, E.G. 2016. Flipping one-shot library instruction: Using Canvas and Pecha Kucha for peer teaching. Journal of the Medical Library Association 104(2):125-30. DOI: 10.3163/1536-5050.104.2.006.

Hufford, J.R. 2004, User instruction for distance students: Texas Tech University System's Main Campus Library reaches out to students at satellite campuses. Journal of Library Administration 41(1/2):153-65.

Nicholson, H. \& Eva, N. 2011. Information literacy instruction for satellite university students. Reference Services Review 39(3):497-513. DOI: 10.1108/00907321111161458.

Miller, M. \& Neyer, L. 2016. Mapping information literacy and written communication outcomes in an undergraduate nursing curriculum: A case study in librarian-faculty collaboration. Pennsylvania Libraries 4(1):20-32. DOI: 10.5195/palrap.2016.121.

Whearty, B., Brunner, M., Johnston, C. \& Turnator, E. 2017. Creating contact zones in a "post-truth" era: Perspectives on librarian/faculty collaboration in information literacy instruction. A Splendid Torch: Learning and Teaching in Today's Academic Libraries, 174:32-68. 